\title{
Influence of microalgae addition in formulation on colour, texture, and extrusion parameters of corn snacks
}

\author{
Zaida Natalia Uribe-Wandurraga, Marta Igual, \\ Purificación García-Segovia $\odot$ and Javier Martínez-Monzó $\circledast$
}

\begin{abstract}
Extrusion is a more and more popular technique for snack production using interesting raw ingredients, to produce snacks improving their nutritional value. The aim of this study was to obtain corn extrudates enriched with different concentration levels of Arthrospira platensis, Chlorella vulgaris, and Nannochloropsis gaditana biomass and to compare their expansion parameters and physicochemical properties with control corn extrudates. Expansion, physicochemical, and compositional parameters were analysed. Microalgae addition to formulations gave extruded snacks and provoked no major changes compared to control corn extrudate. Addition of microalgae in extrudates formulation implies a slight reduction of water absorption index, swelling index, bulk density, and hygroscopicity and a slight increase in water solubility index, expansion index, and porosity. Noticeable changes for the addition of microalgae changed the extruded snack from translucent to opaque and total colour difference values of were perceptible by human eye.
\end{abstract}

\section{Keywords}

Extruded products, microalgae, physical properties, optical properties

Date received: 21 January 2020; accepted: 15 April 2020

\section{INTRODUCTION}

Extrusion processing is a thermally efficient process using high temperature and short time heat treatment and intense shearing under pressure to make a range of food products including expanded snacks, breakfast cereals, and other ready-to-eat textured foods (Chan et al., 2019). The extrusion process, compared with other methods to produce snacks as frying, allows production of low-fat snacks and prompts the formation of resistant starch, which makes no caloric contribution and behaves physiologically like dietary fibre (Larrea et al., 2005). As a result, extrusion is progressively more popular process, using raw materials containing protein, starch, and dietary fibre aids snack creation with increased nutritional value (Šárka et al., 2015).

Food Science and Technology International 26(8) 685-695

(C) The Author(s) 2020 Article reuse guidelines:

sagepub.com/journals-permissions

DOI: $10.1177 / 1082013220924178$

journals.sagepub.com/home/fst

๑SAGE
Thus, microalgae can be a good raw material presenting high nutritive and functional value.

Microalgae biomass is an advantageous source of pigments, vitamins, proteins, fatty acids, sterols, polysaccharides, among other biologically active compounds presenting potential health benefits (Gouveia et al., 2007). Nowadays, there are many commercial applications for microalgae in food. For example, microalgae can be used to enhance the nutritional value of pasta (Fradique et al., 2010), cookies (Batista et al., 2017), and breadsticks (Uribe-Wandurraga et al., 2019) in which breadsticks enrichment with $1.5 \%$ of Chlorella or Spirulina was classed as foods "high in

Food Investigation and Innovation Group, Food Technology Department, Universitat Politècnica de València, Valencia, Spain

Corresponding author:

Javier Martínez-Monzó, Food Technology Department, Universitat Politècnica de València, Camino de Vera s/n., 46022 Valencia, Spain.

Email: xmartine@tal.upv.es 
iron and selenium." Incorporating microalgae in food formulations offers interesting nutritional and functional insight, it is necessary to evaluate its effect on extruded products under process, because of the impact characteristics of the raw materials can have. Among the most important properties of food products obtained through high temperature and low moisture extrusion cooking is expansion. Extrudate expansion is a complex phenomenon influenced by food composition and extrusion processing parameters (Patil et al., 2005). Moreover, expansion-related parameters (water absorption, water solubility, crispiness and crunchiness) are important to determine the quality of the extruded products and their characteristics (Morales et al., 2015). The main studied parameters of the extrudates are the ratio of diameter square, also known as sectional expansion index, the specific density, bulk density, and porosity (Berrios et al., 2004). Besides, there are other physical properties of extrudates such as swelling index, water activity, hygroscopicity, colour, and texture which determinate the extrudates quality.

The aim of this study was to produce corn extrudates enriched with different quantities of Arthrospira platensis, Chlorella vulgaris, and Nannochloropsis gaditana biomass to compare expansion parameters and the physicochemical properties of the extrudates with a control corn extrudate.

\section{MATERIAL AND METHODS}

\section{Raw material}

Corn grits were supplied by Molendum Ingredients S.L. (Spain). Freeze-dried Arthrospira platensis (Spirulina), Chlorella vulgaris, and Nannochloropsis gaditana biomass were supplied from AlgaEnergy S.A. (Madrid, Spain).

\section{Formulations and extrusion processing}

Corn grits (CM) were mixed manually using a whisk, with microalgae (Spirulina, Chlorella, and Nannochloropsis) powder at $0.5,1$, and $1.5 \%$ producing the mixtures SM, CHM, and NM, respectively, at the different concentrations: S0.5M, S1M, S1.5M, CH0.5M, $\mathrm{CH} 1 \mathrm{M}, \mathrm{CH} 1.5 \mathrm{M}, \mathrm{N} 0.5 \mathrm{M}, \mathrm{N} 1 \mathrm{M}$, and N1.5M.

Extrusion was performed using a single-screw laboratory extruder (Kompaktextruder KE 19/25; Brabender, Duisburg, Germany) with a barrel diameter of $19 \mathrm{~mm}$ and a length:diameter ratio of $25: 1$. The extruder was operated at a 3:1 compression ratio, loaded with prepared corn samples at a constant dosing speed of $18 \mathrm{r} / \mathrm{min}$ (feed rate range, $1.58 \mathrm{~kg} / \mathrm{h}$ ). The screw was rotated at a constant $150 \mathrm{r} / \mathrm{min}$, and temperatures of barrel sections 1-4 were set to 25,70 , 170 , and $175{ }^{\circ} \mathrm{C}$, respectively; the nozzle diameter was
$3 \mathrm{~mm}$. Motor torque, screw speed, barrel temperatures, and melt pressure were monitored using Extruder Winext software (Brabender). Calculated specific mechanical energy of corn extrusion ranged from 1400 to $1600 \mathrm{~kJ} / \mathrm{kg}$. Extrudates obtained, CE (Control); S0.5E, S1E, and S1.5E for Spirulina; CH0.5E, CH1E, and CH1.5E for Chlorella; and N0.5E, N1E, and N1.5E for Nannochloropsis, were cooled at $20{ }^{\circ} \mathrm{C}$ and sealed in plastic bags for further analysis.

\section{Analysis}

Water content and water activity. Water content $\left(\mathrm{x}_{\mathrm{w}}\right)$ (g water/100 g sample), for both mixtures and extruded samples, was determined by vacuum oven drying at $105^{\circ} \mathrm{C}$ until constant weight (AOAC, 2005).

Water activity $\left(\mathrm{a}_{\mathrm{w}}\right)$ of the extruded samples was measured using the AquaLab PRE LabFerrer equipment (Pullman, USA) at $20^{\circ} \mathrm{C}$. Samples were analysed in triplicate.

Particle size distribution. Formulated flours' particle size distribution was determined by applying the laser diffraction method and Mie theory, following the ISO13320 standard (ISO Standard International, 2009), using a particle size analyser (Malvern Instruments Ltd., Mastersizer 2000, UK) equipped with a dry sample dispersion unit (Malvern Instruments Ltd., Scirocco 2000). Laser diffraction reports the volume of material of a given size since the light energy reported by the detector system is proportional to the volume of material present. The volume (\%) against particle size $(\mathrm{mm})$ was recorded and the size distribution was characterised by the volume mean diameter ( $\mathrm{D}$ [4.3]). The standard percentiles d (0.1), $\mathrm{d}(0.5)$, and $\mathrm{d}(0.9)$ or the size of particle below which $10 \%, 50 \%$, and $90 \%$ of the sample lies were also considered for formulated flour characterisation. These parameters were estimated using Mastersizer 2000 software (version 5.6) considering the particle diameter.

Expansion index (SEI). Diameter of 20 extruded product pieces $\left(D_{e}\right)$ were measured for each sample, with an electronic Vernier calliper (Comecta S.A., Spain). Equation (1) was used to obtain the surface expansion index of die (SEI) (Patil et al., 2005)

$$
S E I=\frac{D_{e}^{2}}{D_{d}^{2}}
$$

where $D_{d}$ is die diameter $(3 \mathrm{~mm})$.

Bulk density and porosity. The porosity $(\varepsilon)$, or percentage of air volume related to the total volume, was calculated from the true $(\rho)$ and bulk $\left(\rho_{b}\right)$ densities 
according to equation (2).

$$
\varepsilon=\frac{\left(\rho-\rho_{b}\right)}{\rho}
$$

The real density of the extruded products was determined using a helium pycnometer (AccPyc 1330, Micromeritics, Norcross, USA). For the purposes of bulk density $\left(\rho_{b}\right)$ determination, measurements were taken 15 times where the height and diameter of cylinders were measured with an electronic Vernier calliper (Comecta S.A., Spain) and samples were weighed with a precision scale $( \pm 0.001 \mathrm{~g})$ (Mettler Toledo, Switzerland).

Water absorption index, water solubility index, and swelling index. The water solubility index (WSI) and water absorption index (WAI) were determined by the method of Singh and Smith (1997). The extrudates were first milled to a mean particle size of $180-250 \mu \mathrm{m}$. A $2.5 \mathrm{~g}$ sample was dispersed in $25 \mathrm{~g}$ of distilled water, using a rod to break up any lumps. After stirring for 30 min using a magnetic stirrer, the dispersions were rinsed into tared $50 \mathrm{~mL}$ centrifuge tubes, made up to $32.5 \mathrm{~g}$ and centrifuged at $3000 \mathrm{~g}$ for $10 \mathrm{~min}$. The supernatant was decanted for determination of its dissolved solids content and the sediment was weighed.

WAI and WSI were calculated according to equations (3) and (4), respectively.

$$
\mathrm{WAI}=\frac{\text { weight of sediment }}{\text { weight of dry solids }}
$$

$\begin{aligned} \text { WSI }(\%)= & \frac{\text { weight of dissolved solids in supernatant }}{\text { weight of dry solids }} \\ & \times 100\end{aligned}$

The swelling index (SWE) was measured using the bed volume technique. Samples were accurately weighed $(1 \mathrm{~g})$ and transferred to a calibrated cylinder and $10 \mathrm{~mL}$ of distilled was added. Cylinders were left to stand undisturbed for $18 \mathrm{~h}$ at ambient temperature. The bed volume was recorded and expressed as millimetre of swollen sample per gram of dry initial sample (Robertson et al., 2000).

Hygroscopicity. Samples (approximately $0.5 \mathrm{~g}$ ) of each extruded sample were placed at $25^{\circ} \mathrm{C}$ in a Petri dish, in an airtight plastic container containing with $\mathrm{Na}_{2} \mathrm{SO}_{4}$ saturated solution $(81 \% \mathrm{RH})$ at the bottom. After 2, 5 , and 7 days, each sample was weighed and hygroscopicity $(\mathrm{Hg})$ was expressed as gram of water gained per 100 gram dry solids (Cai and Corke 2000).
Optical properties. Translucency and CIE* L*a*b* colour coordinates were determined from the surface reflectance spectra obtained between 400 and $700 \mathrm{~nm}$, when measuring on white and black backgrounds, considering standard light source D65 and a standard observer $10^{\circ}$ (Minolta spectrophotometer CM-3600d, Japan). Measurements were taken 10 times on the extruded samples. The translucency of the samples was determined by applying the Kubelka-Munk theory for multiple scattering of the reflection spectra (Hutchings, 1999; Talens et al., 2002). This theory assumes that the light flux passing through the sample is related to the ratio of absorbed versus scattered light. Spectral distribution of Kubelka-Munk coefficient (ratio between light absorption (K) and scattering (S)) was obtained as follows

$$
\begin{gathered}
\frac{K}{S}=\frac{\left(1-R_{\infty}\right)^{2}}{2 \cdot R_{\infty}} \\
R_{\infty}=a-b \\
a=\frac{1}{2}\left(R+\frac{R_{o}-R+R_{g}}{R_{o} \cdot R_{g}}\right) \\
b=\left(a^{2}-1\right)^{1 / 2}
\end{gathered}
$$

where $R_{\infty}$ is the reflectance of an infinitely thick layer of the material; $R$ and $R_{o}$ are the reflectance of sample over white and ideally black backgrounds, respectively; and $R_{g}$ is the reflectance of the white background. For translucent samples, $R$ and $R_{o}$ take different values. In these cases, to obtain CIEL*a*b* colour coordinates, $R_{\infty}$ was calculated (Hutchings, 1999). When no translucency was observed, $R$ was used to obtain the CIEL*a*b* colour values. The calculated reflectance of an infinitely thick layer of the material was used to obtain the coordinates CIE* $\mathrm{L}^{*} \mathrm{a} * \mathrm{~b}$, the hue $\left(\mathrm{h}_{\mathrm{ab}}^{\circ}\right)$ and the chroma $\left(\mathrm{C}^{*}{ }_{\mathrm{ab}}\right)$ colour attributes. The total colour difference $(\Delta \mathrm{E})$ of extrudates was calculated regarding the control sample.

Texture. The texture of extrudates was measured using a TA-XT2 Texture Analyser (Stable Micro Systems Ltd, Godalming, UK) and software, Texture Exponent (version 6.1.12.0). A puncture test determines the force required to push a cylindrical puncturing device or probe into an extrudate using the texture analyser (Desrumaux et al., 1998). A $2 \mathrm{~mm}$ diameter cylinder was used and the cross-head speed was kept at $0.6 \mathrm{~mm} / \mathrm{s}$ and penetration distance $3 \mathrm{~cm}$; measurements were taken 10 times. The software recorded and analysed the force-time curve and gave an area 
under the curve plot, which represented work $(S)$ done for a given time of displacement $(t)$ of the puncturing device. The force drop $(F)$, compared to each peak represented the local resistance of cell walls and the number of peaks $\left(N_{0}\right)$ were also recorded. These parameters were used to calculate the average puncturing force $\left(F_{m p}\right)$ (equation (9)), average specific force of structural ruptures $\left(F_{S}\right)$ (equation (10)), spatial frequency of structural ruptures $\left(N_{s r}\right)$ (equation (11)), and crispness work $\left(W_{c}\right)$ (equation (12)) according to the following equations where $d$ corresponds to the probe travel distance.

$$
\begin{gathered}
F_{m p}=\frac{S}{t} \\
F_{s}=\operatorname{sum} \text { of } \frac{F}{N_{o}} \\
N_{s r}=\frac{N_{o}}{d} \\
W_{c}=\frac{F_{m p}}{N_{s r}}
\end{gathered}
$$

Statistical analysis. Analysis of variance (ANOVA), with a confidence level of $95 \% \quad(p<0.05)$, using Statgraphics Centurion XVII Software, version 17.2.04, was applied to evaluate the differences among extruded samples. A correlation analysis among the characteristic parameters of extrudates, the studied parameters of mixture flours, and textural properties of extrudates produced in the study, with a $95 \%$ significance level, was conducted (Statgraphics Centurion XVII).

\section{RESULTS AND DISCUSSION}

\section{Particle size of mixtures}

There are few published studies on the influence of food particle size and distribution on processing and extrudate characteristics. For example, Mohamed (1990) using a single-screw extruder on corn grits of $402 \mu \mathrm{m}$ to $618 \mu \mathrm{m}$ average particle sizes found a decrease of melt expansion and an extrudate hardness with increasing particle size. Table 1 shows the particle size of mixtures, characterised by the volume mean diameter and standard percentiles values and mixture's water content. All the samples' trends are similar except for S0.5.M, S1M, and S1.5M (0.5, 1, and $1.5 \%$ Spirulina). Microalgae addition increases significantly $(p<0.05)$ the volume mean diameter (D [4.3]) of mixtures with Spirulina and Chlorella at $1.5 \%$. Spirulina addition at $1.5 \%$ provokes a significant displacement of volume particle size distributions to a higher particle size. S1.5M showed a higher percent of volume at $500 \mu \mathrm{m}$ of particle size. However, Nannochloropsis mixtures did not show significant differences $(p>0.05)$ in particle size with respect to control mixtures. S1.5M showed the highest significant $(p<0.05)$ differences compared with the control, followed by $\mathrm{CH} 1.5 \mathrm{M}$. Values for $\mathrm{d}(0.1), \mathrm{d}(0.5)$, and $\mathrm{d}(0.9)$ presented a similar trend to D [4.3]. Regarding water content (Table 1), $\mathrm{CM}$ presented slightly lower values than the other mixtures.

Table 1. Mean values (and standard deviations) of water content $\left(x_{w}, g_{w} / g\right)$, volume mean diameter $(\mu \mathrm{m}) \mathrm{D}[4,3]$, standard percentiles $(\mu \mathrm{m}) \mathrm{d}(0.1), \mathrm{d}(0.5)$, and $\mathrm{d}(0.9)$ of used mixture flours.

\begin{tabular}{lcllcl}
\hline & $\mathrm{x}_{\mathrm{w}}$ & $\mathrm{D}[4,3]$ & $\mathrm{d}(0.1)$ & $\mathrm{d}(0.5)$ & $\mathrm{d}(0.9)$ \\
\hline $\mathrm{CM}$ & $0.094(0.003)^{\mathrm{c}}$ & $503(5)^{\mathrm{c}}$ & $271(14)^{\mathrm{b}}$ & $480(6)^{\mathrm{c}}$ & $784(24)^{\mathrm{c}}$ \\
S0.5M & $0.097(0.002)^{\mathrm{abc}}$ & $509(2)^{\mathrm{bc}}$ & $271(2)^{\mathrm{b}}$ & $485.5(1.5)^{\mathrm{bc}}$ & $798(3)^{\mathrm{bc}}$ \\
S1M & $0.0968(0.0009)^{\mathrm{abc}}$ & $509(3)^{\mathrm{bc}}$ & $272(3)^{\mathrm{b}}$ & $487(3)^{\mathrm{bc}}$ & $798(4)^{\mathrm{bc}}$ \\
S1.5M & $0.0971(0.0007)^{\mathrm{ab}}$ & $540(24)^{\mathrm{a}}$ & $305(23)^{\mathrm{a}}$ & $513(19)^{\mathrm{a}}$ & $826(26)^{\mathrm{a}}$ \\
CH0.5M & $0.09657(0.00103)^{\mathrm{abc}}$ & $509(4)^{\mathrm{bc}}$ & $274(3)^{\mathrm{b}}$ & $486(4)^{\mathrm{bc}}$ & $796(5)^{\mathrm{bc}}$ \\
CH1M & $0.096(0.003)^{\mathrm{abc}}$ & $511(3)^{\mathrm{bc}}$ & $274(2)^{\mathrm{b}}$ & $489(4)^{\mathrm{b}}$ & $799(6)^{\mathrm{b}}$ \\
CH1.5M & $0.0971(0.0004)^{\mathrm{ab}}$ & $514(3)^{\mathrm{b}}$ & $279(3)^{\mathrm{b}}$ & $491(3)^{\mathrm{b}}$ & $800(4)^{\mathrm{b}}$ \\
N0.5M & $0.09604(0.00107)^{\mathrm{bc}}$ & $512(2)^{\mathrm{bc}}$ & $281(2)^{\mathrm{b}}$ & $488(2)^{\mathrm{b}}$ & $793(3)^{\mathrm{b}}$ \\
N1M & $0.09883(0.00108)^{\mathrm{a}}$ & $508(4)^{\mathrm{bc}}$ & $272(5)^{\mathrm{b}}$ & $486(4)^{\mathrm{bc}}$ & $795(4)^{\mathrm{bc}}$ \\
N1.5M & $0.0958(0.0006)^{\mathrm{bc}}$ & $508(3)^{\mathrm{bc}}$ & $272(3)^{\mathrm{b}}$ & $486(3)^{\mathrm{bc}}$ & $795(4)^{\mathrm{bc}}$ \\
\hline
\end{tabular}

Mixtures obtained (M): CM (Control); S0.5M, S1M, and S1.5M for Spirulina (S) at 0.5, 1, and 1.5\%, respectively; $\mathrm{CH} 0.5 \mathrm{M}, \mathrm{CH} 1 \mathrm{M}$, and $\mathrm{CH} 1.5 \mathrm{M}$ for Chlorella $(\mathrm{CH})$ at $0.5,1$, and $1.5 \%$, respectively; and $\mathrm{N} 0.5 \mathrm{M}, \mathrm{N} 1 \mathrm{M}$, and $\mathrm{N} 1.5 \mathrm{M}$ for Nannochloropsis $(\mathrm{N})$ at $0.5,1$, and $1.5 \%$, respectively. The same letter in superscript within column indicates homogeneous groups established by ANOVA $(p<0.05)$. 


\section{Physicochemical characteristics of extrudates}

The physicochemical properties of the extrudates are direct indicators of the effect on product quality from raw material characteristics and processing variables. Figures 1 to 3 represent water content $\left(\mathrm{x}_{\mathrm{w}}\right)$ and water activity $\left(\mathrm{a}_{\mathrm{w}}\right)$; WAI, WSI, swelling index (SWE), and surface expansion index of die (SEI); and bulk density $\left(\rho_{b}\right)$, porosity $(\varepsilon)$, and hygroscopicity $(\mathrm{Hg})$, respectively. Water content (Figure 1(a)) and water activity (Figure 1(b)) were in the range of low moisture foods. All microalgae formulations showed water content significantly $(p<0.05)$ lower than the control, except to $\mathrm{CH} 1.5 \mathrm{E}$. Moisture losses during extrusion process in samples with microalgae addition were higher that moisture losses in control samples (Table 1). This may be explained by moisture loss at the die is dependent on the vapour pressure inside the air cells and matrix characteristics such as extensibility and water binding, reflecting the degree of starch transformation (Karkle et al., 2012). However, there are no significant $(p>0.05)$ differences among samples regarding water activity (Figure 1(b)).

The qualitative characteristics of the extruded products are shown in Figure 2. WAI indicates the quantity of water immobilised by the extrudate, while WSI indicates the quantity of small molecules solubilised in water causing molecular damage in the process (Mezreb et al., 2003). The WAI and WSI can be used to calculate approximately the functional characteristics of foods and predict the behaviour of the materials during processing (De Mesa et al., 2009). Microalgae addition in formulations in extrudates decreased the WAI (Figure 2(a)), when the concentrations are high $(1.5 \%)$. We believe this trend is because of reduced starch gelatinisation as the starch has depolymerised to some range, consequently losing water absorption capacity (Karkle et al., 2012). Also, these differences could be related to the competition between algae and starch for water during gelatinisation, which could be limiting this phenomenon. WSI (Figure 2(b)) presented the opposite behaviour to WAI. WSI increased with the addition of microalgae but in NE there were no significant $(p>0.05)$ differences. CHE showed significant differences with respect to the control, and SE only when Spirulina concentrations were 0.5 and $1.5 \%$. Other researchers suggested that increasing WSI is caused by greater shear degradation of starch during extrusion at low moisture conditions (Onyango et al., 2004). WAI and WSI values of control and microalgae extrudates are in the ranges for extrudates food products presented by Oikonomou and Krokida (2011). The swelling index (Figure 2(c)), alike the water holding capacity, is determined by the bed volume technique by a static method (Patil et al., 2005). There were no SWE values significantly $(p>0.05)$ higher than the value of the control. S0.5E, N1E, and N1.5E showed no significant $(p>0.05)$ differences with the control. However, the rest of the extrudates presented SWE values significantly $(p<0.05)$ lower than the control. Expansion depends on the food composition, degree of cooking, and melt flow index in the die. Besides, expansion at the die defines the extrudates' final texture (Desrumaux et al., 1998). The expansion ratio and bulk density of extrudates describe the degree of puffing to be put through by the material as it exits the extruder (Keawpeng et al., 2014). Sectional expansion index considers only expansion, in the perpendicular direction to the extrudate flow (Saldanha do Carmo et al., 2019), while bulk density considers expansion in all directions (Desta et al., 2019). SEI increased when microalgae
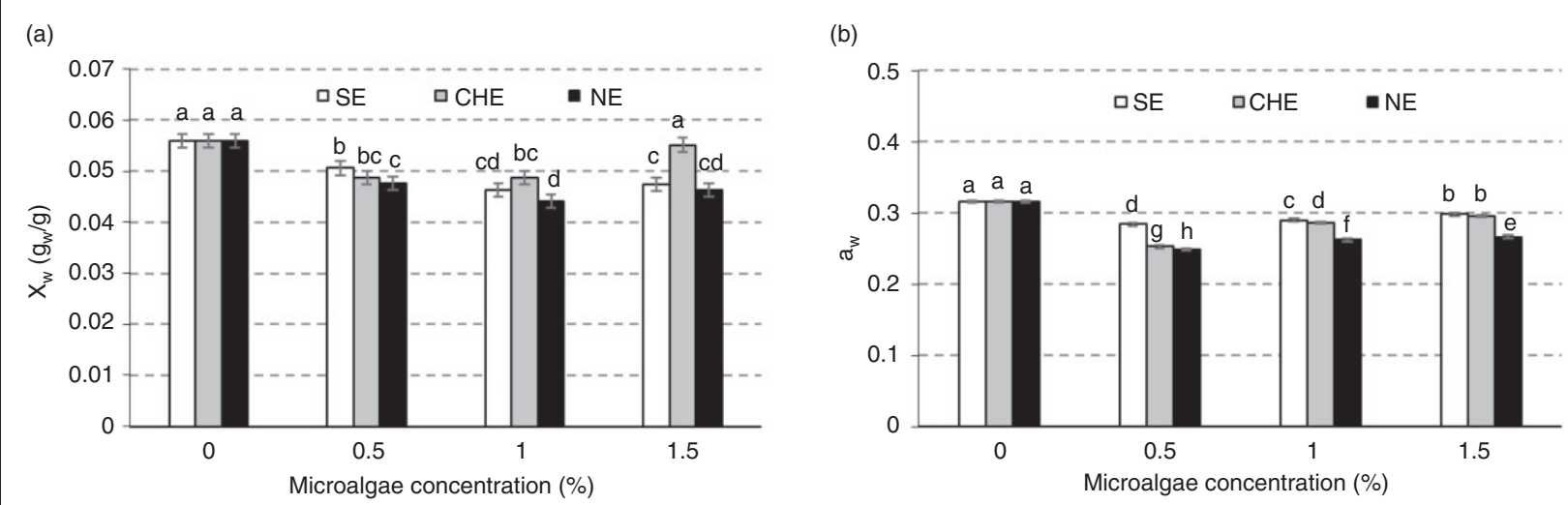

Figure 1. Mean values and LSD (Least Significant Difference) intervals of (a) water content $\left(x_{w}\right)$ and $(b)$ water activity $\left(a_{w}\right)$ of each extrudate, SE, CHE, and NE, according to microalgae concentration (\%).

SE: Spirulina; CHE: Chlorella; NE: Nannochloropsis. 


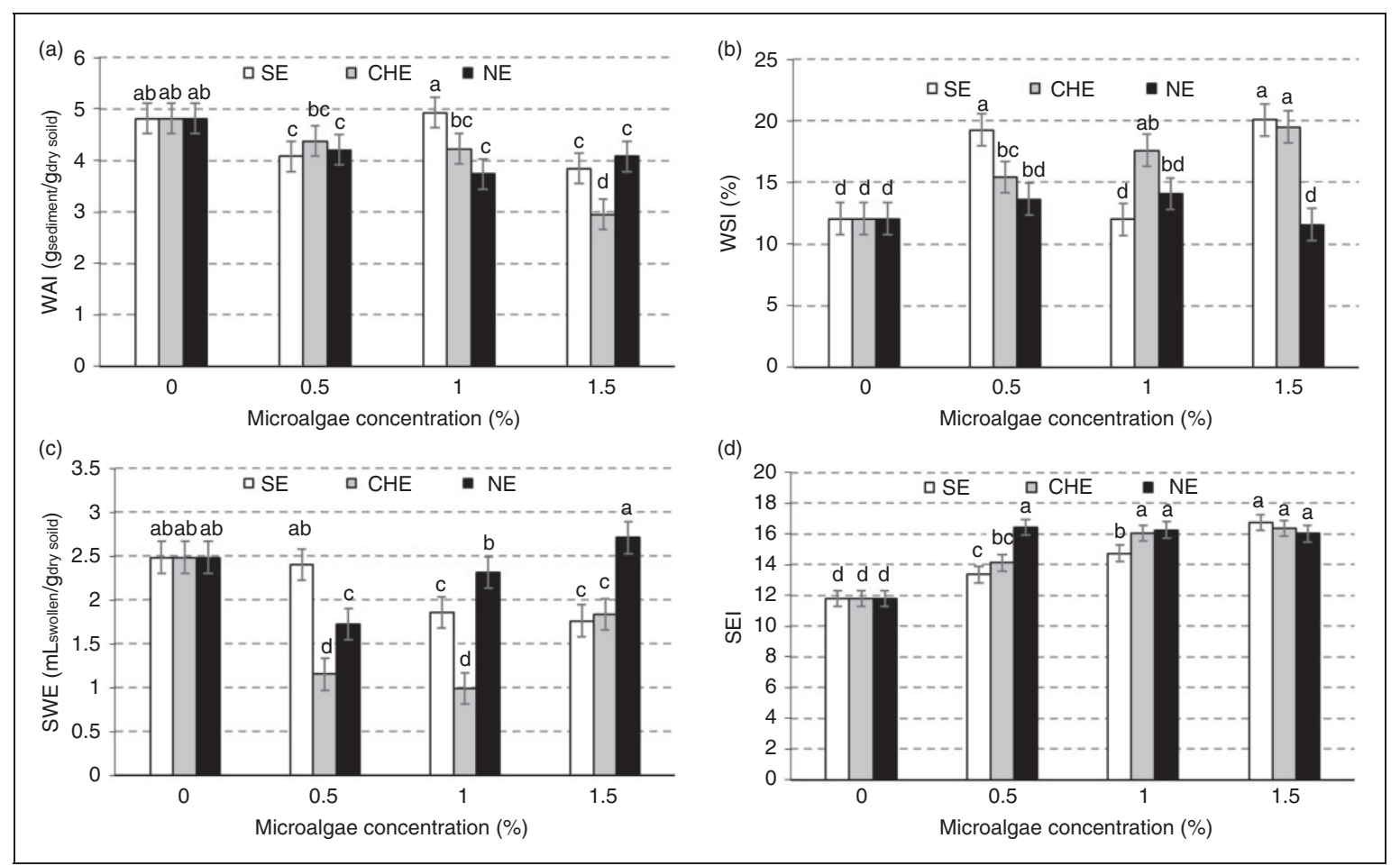

Figure 2. Mean values and LSD (Least Significant Difference) intervals of (a) water absorption index (WAI); (b) water solubility index (WSI); (c) swelling index (SWE); and (d) expansion index (SEI) of each extrudate, SE, CHE, and NE, according to microalgae concentration (\%).

SE: Spirulina; CHE: Chlorella; NE: Nannochloropsis.

were added in the formulations. The effect of concentration was evident in SEI for all concentrations and $\mathrm{CHE}$ at 0.5 and $1 \%$; NE was not affected by concentration levels. The extrudate with higher SEI was N0.5E. Figure 3 shows mean values and least significant difference intervals of bulk density $\left(\rho_{b}\right)$, porosity $(\varepsilon)$, and hygroscopicity $(\mathrm{Hg})$. Density is a general property of the extrudate, which indicates overall expansion and changes in material parameters plus cell structure, pores, and voids developed as the effect of processing; highly expanded extruded materials show a porous structure. Dullien (1991) reported that the void spaces in extrudates had interconnected pore segments, accessible on both ends; dead-end or blind pore segments, accessible only at one end; and non-interconnected pores, inaccessible pores on the interior of the solid. As a consequence, interconnected and dead-end pores can be observed as open pores whereas non-interconnected pores, as closed pores (Patil et al., 2005). The $\rho_{b}$ decreased significantly $(p<0.05)$ with the use of microalgae in formulations. Furthermore, there was a trend of $\rho_{b}$ decreases with the increase of microalgae concentrations (Figure 3(a)). The addition of Chlorella or Nannochloropsis in any concentration significantly increased $(p<0.05)$ porosity (Figure 3(b)). However, the addition of Spirulina at 0.5 and $1 \%$ showed no significant $(p>0.05)$ differences in porosity; at $1.5 \%$ the values increased significantly $(p<0.05)$ (Figure 3(b)). SM hygroscopicity showed no significant $(p<0.05)$ differences in comparison with the control (Figure 3(c)). Nevertheless, CHE and NE presented significant $(p<0.05)$ differences with respect to CE in any microalgae concentration. The less hygroscopic extrudate was N1.5E, with the water gained per $100 \mathrm{~g}$ of dry solid was lower than the rest of the samples.

Pearson correlation coefficients among studied parameters of extruded products were obtained. There were significant $(p<0.05)$ correlations among SEI with $\mathrm{X}_{\mathrm{w}}(-0.5161)$, WAI $(-0.5123)$, hygroscopicity $(-0.6228), \rho_{b}(-0.8172)$, and $\varepsilon(0.6221)$. When the values of SEI are greater, the values of $x_{\mathrm{w}}$, WAI, hygroscopicity, $\rho_{b}$ are lower but $\varepsilon$ is greater. Bulk density $\left(\rho_{b}\right)$ presented the highest Pearson coefficient with SEI $(-0.8172)$ and showed a high correlation with $\mathrm{Hg}$ (0.7223); porosity showed a reverse correlation with $\mathrm{Hg}(-0.5472)$.

When the corn flour was combined with microalgae, the diameter of extrudates increases but the perimeter of extrudates with microalgae is more irregular. This fact is because of the pore size, which is bigger in snacks with microalgae than those of the control sample (Figure 4). 


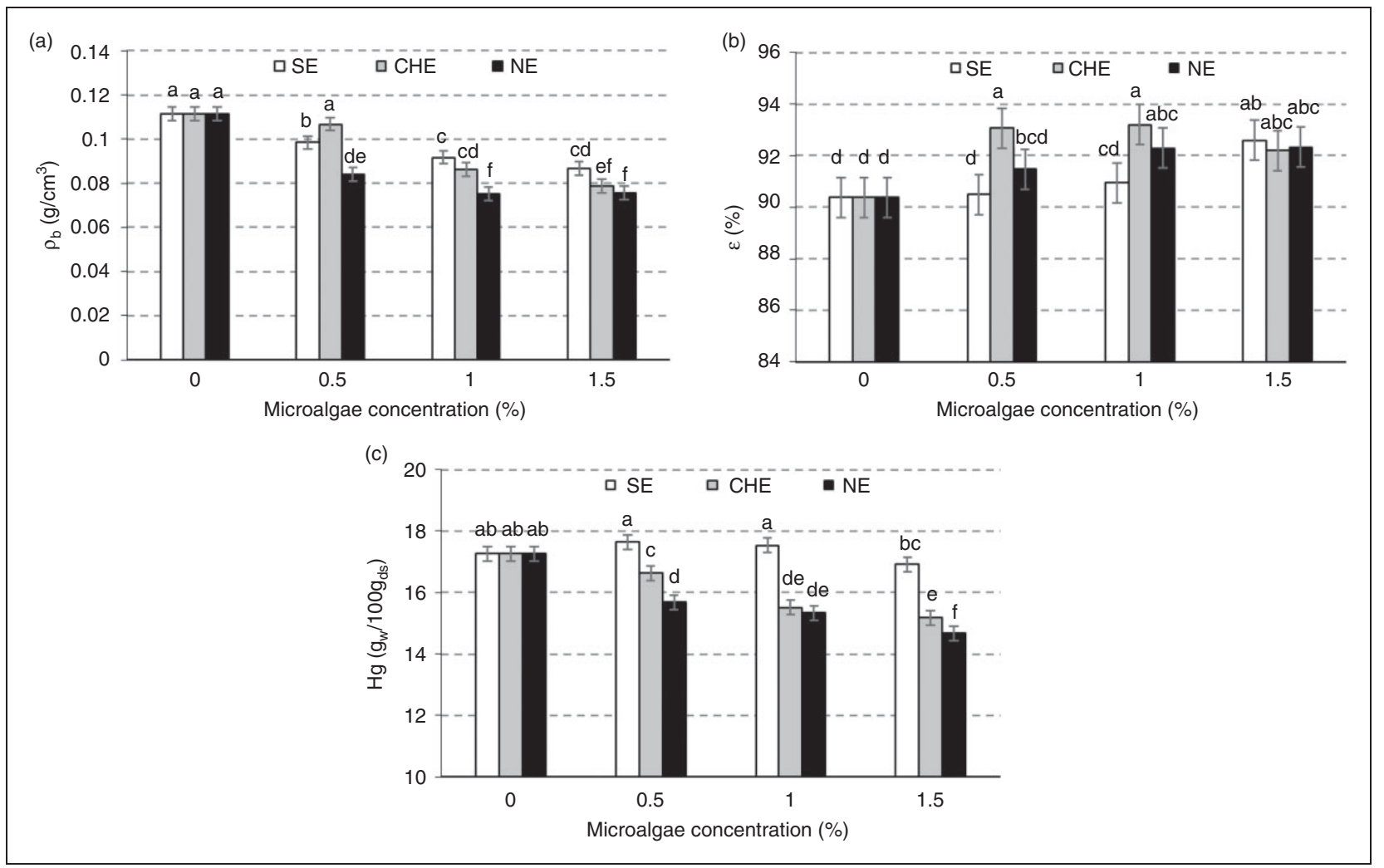

Figure 3. Mean values and LSD (Least Significant Difference) intervals of (a) bulk density $\left(\rho_{b}\right)$; (b) porosity $(\varepsilon)$; and (c) hygroscopicity $(\mathrm{Hg})$ of each extrudate, SE, CHE, and NE, according to microalgae concentration (\%).

SE: Spirulina; CHE: Chlorella; NE: Nannochloropsis.

\section{Optical properties of extrudates}

To quantify the snack translucency, the analysis of spectral distribution of Kubelka-Munk coefficients obtained from reflectance spectra was conducted; the greater the $\mathrm{K} / \mathrm{S}$ values, the greater the product translucency (Hutchings, 1999). From the reflection spectra in the visible range, the colour coordinates $C I E * L^{*} a * b *$ and the values of the chroma $\left(\mathrm{C}^{*}{ }_{\mathrm{ab}}\right)$ and tone $\left(\mathrm{h}^{\circ}{ }_{\mathrm{ab}}\right)$ were obtained in control extrudates. Samples with microalgae presented no differences between measurements on white and black backgrounds so they were not translucent. The addition of microalgae changed the extruded snack from translucent to opaque.

Here, the colour coordinates CIE* L*a*b* were obtained directly from equipment. Table 2 shows $\mathrm{L}^{*}$, $\mathrm{a}^{*}, \mathrm{~b}^{*}, \mathrm{C}^{*}{ }_{\mathrm{ab}}, \mathrm{h}_{\mathrm{ab}}^{\circ}$, and $\Delta \mathrm{E}$ of studied extrudates. The microalgae addition in extrudate mixtures decreases luminosity $\left(\mathrm{L}^{*}\right)$ of the product. Higher Spirulina or Chlorella concentrations in extrudates provoked lower L* coordinates; however, Nannochloropsis concentration effected no change for $\mathrm{L}^{*}$. The incorporation of Nannochloropsis did not significantly $(p>0.05)$ effect $a^{*}, b^{*}$, and $C^{*}{ }_{a b}$ parameters, independently of concentration used. Extrudates with Spirulina or Chlorella in their composition showed values of a*, significantly $(p<0.05)$ lower than the control, having a less reddish colour. When increasing the Spirulina or Chlorella concentration $\mathrm{a} *$ decreased but $\mathrm{h}_{\mathrm{ab}}^{\circ}$ increased slightly. The $\mathrm{h}_{\mathrm{ab}}^{\circ}$ values are very near to $90^{\circ}$, so the samples are mainly yellow as can be seen in Figure 4. The higher tone was present in the $\mathrm{CH} 1.5 \mathrm{E}$ sample since its $\mathrm{a}^{*}$ value was lower. The values of $\mathrm{C}^{*}{ }_{\mathrm{ab}}$ and $\mathrm{b}^{*}$ are similar because $a^{*}$ values are approximate to 0 . The total colour difference values of the extrudates are $\Delta E>3$ and is considered humanly perceptible (Bodart et al., 2008). As the other colour parameters, concentration effects are seen with Spirulina and Chlorella; however, this effect is not evident in NE.

\section{Textural characteristics of extrudates}

Texture is very important for ready-to-eat snack products, where crunchiness is a desirable attribute (Patil et al., 2005). Texture parameters studied are showed in Table 3. Crispness work $\left(W_{c}\right)$ describes the work required to fracture one pore or a group of pores and can be interpreted as the sensory parameter of fracturability. Average puncturing force $\left(F_{p}\right)$ and average specific force of structural ruptures $\left(F_{s r}\right)$ of extruded 


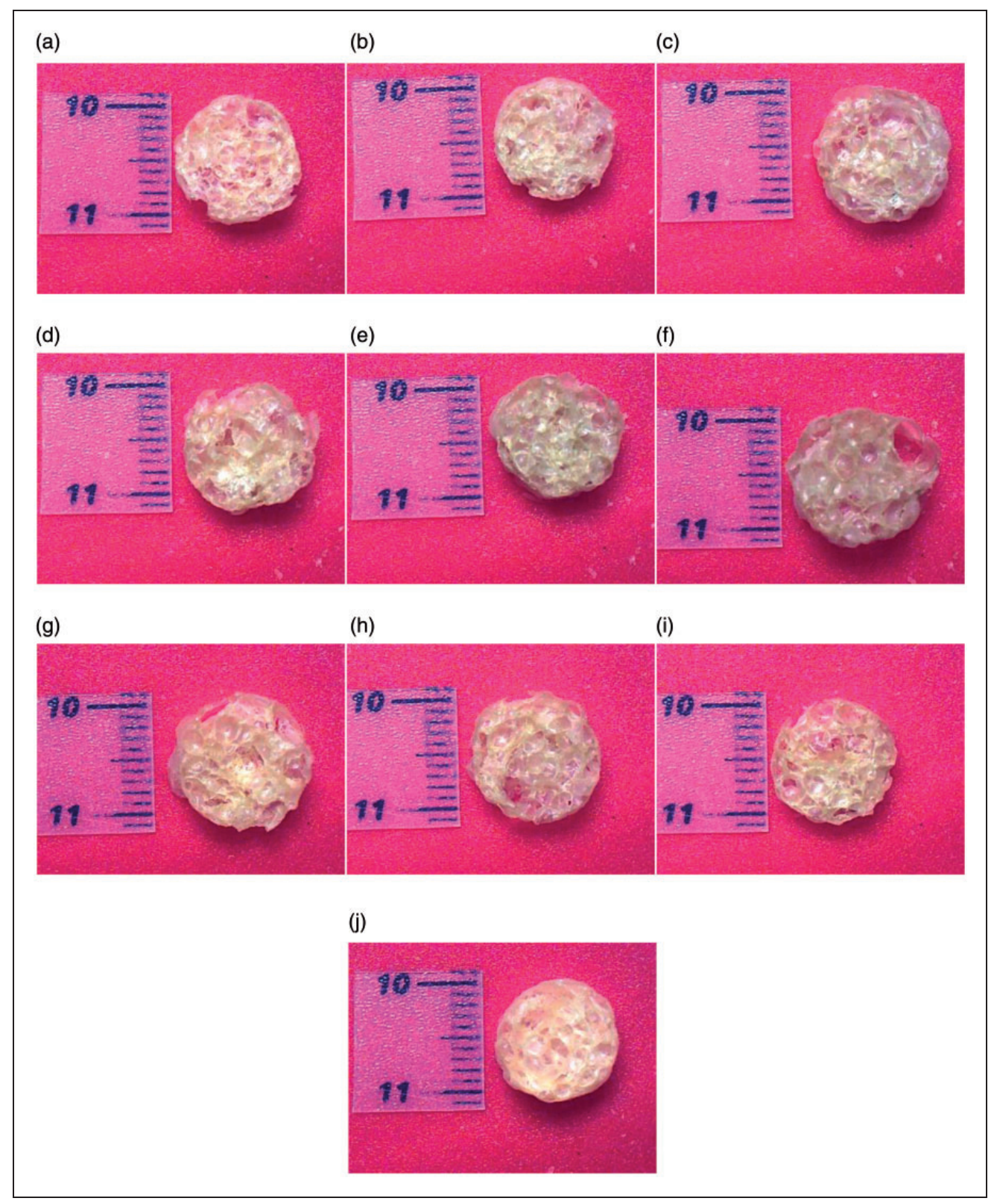

Figure 4. Transversal section pictures of each extrudate: S0.5E (a), S1E (b), S1.5E (c), CH0.5E (d), CH1E (e), CH1.5E (f), N0.5E (g), N1E (h), N1.5E (i), and CE (j). CE (Control); S0.5E, S1E, and S1.5E for Spirulina (S) at 0.5, 1, and 1.5\%, respectively; $\mathrm{CH} 0.5 \mathrm{E}, \mathrm{CH} 1 \mathrm{E}$ and $\mathrm{CH} 1.5 \mathrm{E}$ for Chlorella $(\mathrm{CH})$ at $0.5,1$, and $1.5 \%$, respectively; and $\mathrm{N0.5E}, \mathrm{N} 1 \mathrm{E}$, and $\mathrm{N} 1.5 \mathrm{E}$ for Nannochloropsis $(\mathrm{N})$ at $0.5,1$, and $1.5 \%$, respectively.

products are usually associated with the sensory perception of hardness during chewing, which is defined as the force to compress a substance between the molar teeth in the case of solids (Azzollini et al., 2018). Spatial frequency of ruptures $\left(N_{s r}\right)$ describes the number of fracture events occurring during puncture and $\left(N_{0}\right)$ is the number of fractures along the assay. Higher Spirulina or Chlorella concentrations in formulation show lower values of studied mechanical parameters. However, higher Nannochloropsis concentration in formulation shows higher values of $W_{c}, N_{s r}, N_{0}$, and
$F_{m p}$. S1E was the most like the control in mechanical parameter terms. There are no significant $(p>0.05)$ differences between them with respect to studied extrudates. The Chlorella addition provoked the highest significant $(p<0.05)$ changes of texture in extrudates samples, at 1 and $1.5 \%$. The ingredient composition and moisture content of the mix are main factors that affect the texture of the final extrudate. The extruded materials are highly hygroscopic and hence their texture is affected if they are exposed to a humid atmosphere (Patil et al., 2005). Pearson's statistical correlation 
Table 2. Mean values (and standard deviations) of colour coordinates $\left(\mathrm{L}^{*}, \mathrm{a}^{*}, \mathrm{~b}^{*}, \mathrm{C}^{*}{ }_{\mathrm{ab}}\right.$, and $\left.\mathrm{h}_{\mathrm{ab}}^{\circ}\right)$ and total colour differences $(\Delta \mathrm{E})$.

\begin{tabular}{|c|c|c|c|c|c|c|}
\hline & $L^{*}$ & $a^{*}$ & $b^{*}$ & $\mathrm{C}^{\star}{ }_{\mathrm{ab}}$ & $\mathrm{h}^{\circ}{ }_{\mathrm{ab}}$ & $\Delta \mathrm{E}$ \\
\hline CE & $53(4)^{a}$ & $1.7(0.4)^{\mathrm{a}}$ & $29.1(1.5)^{\mathrm{a}}$ & $29.1(1.5)^{\mathrm{a}}$ & $86.6(0.7)^{d}$ & - \\
\hline S0.5E & $51(3)^{a}$ & $1.2(0.5)^{b}$ & $26(2)^{a b c}$ & $26(2)^{\mathrm{bcd}}$ & $87.5(0.9)^{\mathrm{C}}$ & $5(2)^{e}$ \\
\hline S1E & $47(5)^{c}$ & $0.7(0.5)^{c}$ & $24(2)^{\text {ef }}$ & $24(2)^{f g}$ & $88.46(1.02)^{b}$ & $9(4)^{b}$ \\
\hline $\mathrm{S} 1.5 \mathrm{E}$ & $43(3)^{d}$ & $0.4(0.4)^{c}$ & $22(2)^{g}$ & $22(2)^{g}$ & $89.1(0.9)^{b}$ & $12(2)^{a}$ \\
\hline $\mathrm{CH} 0.5 \mathrm{E}$ & $49(3)^{\mathrm{b}}$ & $0.6(0.7)^{\mathrm{c}}$ & $25(2)^{\mathrm{bcd}}$ & $25(2)^{\text {cde }}$ & $88.7(1.4)^{b}$ & $6.5(1.4)^{\mathrm{de}}$ \\
\hline $\mathrm{CH} 1 \mathrm{E}$ & $42(4)^{d}$ & $0.5(0.6)^{c}$ & $25(3)^{\mathrm{cd}}$ & $25(3)^{\mathrm{de}}$ & $89.0(1.2)^{b}$ & $12(3)^{a}$ \\
\hline $\mathrm{CH} 1.5 \mathrm{E}$ & $41(5)^{d}$ & $-0.1(0.6)^{d}$ & $24(3)^{\mathrm{de}}$ & $24(3)^{\text {ef }}$ & $90.3(1.3)^{a}$ & $13(5)^{a}$ \\
\hline N0.5E & $47(5)^{\mathrm{bc}}$ & $1.5(0.5)^{\mathrm{a}}$ & $26(2)^{a b}$ & $26(2)^{\mathrm{bc}}$ & $86.8(0.9)^{d}$ & $7(3)^{\mathrm{cd}}$ \\
\hline $\mathrm{N} 1 \mathrm{E}$ & $46(6)^{c}$ & $1.5(0.8)^{\mathrm{a}}$ & $27(3)^{a}$ & $27(3)^{b}$ & $86.9(1.3)^{\mathrm{cd}}$ & $8(5)^{\mathrm{bcd}}$ \\
\hline $\mathrm{N} 1.5 \mathrm{E}$ & $46(5)^{c}$ & $1.3(0.7)^{\mathrm{ab}}$ & $26(3)^{\mathrm{abc}}$ & $26(3)^{b c d}$ & $87.2(1.2)^{\mathrm{cd}}$ & $8(4)^{\mathrm{bc}}$ \\
\hline
\end{tabular}

Extrudates obtained $(\mathrm{E})$ : CE (Control); S0.5E, S1E, and S1.5E for Spirulina (S) at $0.5,1$, and 1.5\%, respectively; $\mathrm{CH} 0.5 \mathrm{E}, \mathrm{CH} 1 \mathrm{E}$, and $\mathrm{CH} 1.5 \mathrm{E}$ for Chlorella $(\mathrm{CH})$ at $0.5,1$, and $1.5 \%$ respectively; and N0.5E, N1E, and N1.5E for Nannochloropsis $(\mathrm{N})$ at $0.5,1$, and $1.5 \%$ respectively. The same letter in superscript within column indicates homogeneous groups established by ANOVA $(p<0.05)$.

Table 3. Mean values (and standard deviations) of texture parameters of extrudates: number of peaks $\left(N_{0}\right)$, average puncturing force $\left(F_{m p}\right)$, average specific force of structural ruptures $\left(F_{s}\right)$, spatial frequency of structural ruptures $\left(N_{s r}\right)$, and crispness work $\left(W_{c}\right)$.

\begin{tabular}{llcccc}
\hline & $W_{c}(\mathrm{~N} \cdot \mathrm{mm})$ & $N_{s r}\left(\mathrm{~mm}^{-1}\right)$ & $F_{s}(\mathrm{~N})$ & $F_{m p}(\mathrm{~N})$ & $N_{0}$ \\
\hline $\mathrm{CE}$ & $0.15(0.02)^{\mathrm{a}}$ & $12.070(1.012)^{\mathrm{a}}$ & $2.2(0.2)^{\mathrm{a}}$ & $1.8(0.2)^{\mathrm{a}}$ & $131(11)^{\mathrm{ab}}$ \\
S0.5E & $0.12(0.02)^{\mathrm{bc}}$ & $11.3(0.9)^{\mathrm{ab}}$ & $1.8(0.2)^{\mathrm{bc}}$ & $1.39(0.13)^{\mathrm{bc}}$ & $131(9)^{\mathrm{ab}}$ \\
$\mathrm{S} 1 \mathrm{E}$ & $0.13(0.03)^{\mathrm{bc}}$ & $10.83(1.04)^{\mathrm{b}}$ & $2.0(0.5)^{\mathrm{ab}}$ & $1.6(0.4)^{\mathrm{ab}}$ & $129(18)^{\mathrm{ab}}$ \\
S1.5E & $0.12(0.01)^{\mathrm{bcd}}$ & $9.424(1.012)^{\mathrm{cde}}$ & $1.57(0.14)^{\mathrm{cd}}$ & $1.12(0.19)^{\mathrm{de}}$ & $122(17)^{\mathrm{ab}}$ \\
$\mathrm{CH} 0.5 \mathrm{E}$ & $0.10(0.01)^{\mathrm{d}}$ & $11.2(0.9)^{\mathrm{ab}}$ & $1.50(0.17)^{\mathrm{cde}}$ & $1.13(0.13)^{\mathrm{de}}$ & $135(11)^{\mathrm{a}}$ \\
$\mathrm{CH} 1 \mathrm{E}$ & $0.10(0.02)^{\mathrm{d}}$ & $8.9(1.3)^{\mathrm{de}}$ & $1.30(0.15)^{\mathrm{e}}$ & $0.93(0.17)^{\mathrm{e}}$ & $106(18)^{\mathrm{cd}}$ \\
$\mathrm{CH} 1.5 \mathrm{E}$ & $0.14(0.02)^{\mathrm{ab}}$ & $8.6(1.4)^{\mathrm{e}}$ & $1.6(0.2)^{\mathrm{cd}}$ & $1.2(0.2)^{\mathrm{cde}}$ & $101(16)^{\mathrm{d}}$ \\
N0.5E & $0.11(0.02)^{\mathrm{cd}}$ & $9.7(0.9)^{\mathrm{cd}}$ & $1.5(0.2)^{\mathrm{de}}$ & $1.06(0.16)^{\mathrm{de}}$ & $118(12)^{\mathrm{bc}}$ \\
N1E & $0.11(0.02)^{\mathrm{cd}}$ & $11.0(0.6)^{\mathrm{ab}}$ & $1.6(0.4)^{\mathrm{cd}}$ & $1.2(0.3)^{\mathrm{cd}}$ & $128(6)^{\mathrm{ab}}$ \\
$\mathrm{N} 1.5 \mathrm{E}$ & $0.10(0.02)^{\mathrm{d}}$ & $10.21(1.06)^{\mathrm{bc}}$ & $1.5(0.3)^{\mathrm{cde}}$ & $1.2(0.3)^{\mathrm{cde}}$ & $124(10)^{\mathrm{ab}}$ \\
\hline
\end{tabular}

Extrudates obtained (E): CE (Control); S0.5E, S1E, and S1.5E for Spirulina (S) at $0.5,1$, and 1.5\%, respectively; $\mathrm{CH} 0.5 \mathrm{E}, \mathrm{CH} 1 \mathrm{E}$, and $\mathrm{CH} 1.5 \mathrm{E}$ for Chlorella $(\mathrm{CH})$ at $0.5,1$, and $1.5 \%$, respectively; and N0.5E, N1E, and N1.5E for Nannochloropsis $(\mathrm{N})$ at $0.5,1$, and $1.5 \%$, respectively. The same letter in superscript within column indicates homogeneous groups established by ANOVA $(p<0.05)$.

analysis was used to prove correlations between the mechanical parameters and the characteristic parameters of extrudates. $F_{s}$ and $F_{m p}$ showed positive correlations with hygroscopicity, being $0.61(p<0.05)$ and $0.60(p<0.05)$, respectively. However, $N_{s r}$ was negatively related to SEI $(-0.72, p<0.05)$; when the expansion index is higher, the number of fracture events occurring during puncture is lower, because the pores size is bigger. Alternatively, samples with lower values of expansion index (SEI) presented higher resistance to fracture $\left(W_{c},-0.57, p<0.05\right)$ and hardness $\left(F_{s},-0.60, p<0.05 ; F_{m p},-0.65, p<0.05\right)$ according negative Pearson correlations, because of a higher compaction of extrudates. According to Pearson correlations, lower values of porosity are related with higher values of $F_{s}$ and $F_{m p},-0.67$ and $-0.69 \quad(p<0.05)$, respectively. Comparable results were obtained by other authors (Azzollini et al., 2018; Chanvrier et al., 2014), showing that force is negatively correlated with porosity fraction when they studied extruded snacks.

\section{CONCLUSIONS}

Microalgae addition to formulations for production of extruded snacks provoked no major changes with respect to control corn extrudates. In general, addition 
of microalgae in extrudates formulation implies a reduction of bulk density and hygroscopicity and an increase in porosity. The total colour difference values of extrudates were perceptible to the human eye, producing samples with less luminosity and reddish colour. This effect was less evident in samples with Nannochloropsis. Extrudates with Spirulina or Chlorella in their composition showed greater greenish tone than the control. Higher Spirulina or Chlorella concentrations in formulation show lower values of studied mechanical parameters. Produced snacks showed expansion parameters and physicochemical properties suitable for this kind of process.

\section{ACKNOWLEDGEMENTS}

The authors thank Dr Phillip Bentley who helped to review English language.

\section{DECLARATION OF CONFLICTING INTERESTS}

The author(s) declared no potential conflicts of interest with respect to the research, authorship, and/or publication of this article.

\section{FUNDING}

The author(s) received no financial support for the research, authorship, and/or publication of this article.

\section{ORCID IDS}

Purificación García-Segovia (D) https://orcid.org/0000-00024968-5050

Javier Martínez-Monzó (D) https://orcid.org/0000-0002-11232304

\section{REFERENCES}

AOAC. (2005). Official Methods of Analysis. 18th ed. Association of Official Analytical Chemists: Arlington, VA, USA.

Azzollini D, Derossi A, Fogliano V, et al. (2018). Effects of formulation and process conditions on microstructure, texture and digestibility of extruded insect-riched snacks. Innov Food Sci Emerg Technol 45: 344-353.

Batista AP, Niccolai A, Fradinho P, et al. (2017). Microalgae biomass as an alternative ingredient in cookies: Sensory, physical and chemical properties, antioxidant activity and in vitro digestibility. Algal Res 26: 161-171.

Berrios J de J, Wood DF, Whitehand L and Pan J. (2004). Sodium Bicarbonate and the microestructure, expansion and color of extruded black beans. J Food Process Preserv 28: 321-335.

Bodart M, de Peñaranda R, Deneyer A and Flamant G. (2008). Photometry and colorimetry characterisation of materials in daylighting evaluation tools. Build Environ 43: 2046-2058.

Cai YZ and Corke H. (2000). Production and properties of spray-dried amaranthus betacyanin pigments E. J Food Sci 65: 1248-1252.
Chan E, Masatcioglu TM and Koksel F. (2019). Effects of different blowing agents on physical properties of extruded puffed snacks made from yellow pea and red lentil flours. J Food Process Eng 42: 1-8.

Chanvrier H, Jakubczyk E, Gondek E and Gumy J-C. (2014). Insights into the texture of extruded cereals: Structure and acoustic properties. Innov Food Sci Emerg Technol 24: 61-68.

De Mesa NJE, Alavi S, Singh N, et al. (2009). Soy proteinfortified expanded extrudates: Baseline study using normal corn starch. J Food Eng 90: 262-270.

Desrumaux A, Bouvier JM and Burri J. (1998). Corn grits particle size and distribution effects on the characteristics of expanded extrudates. J Food Sci 63: 857-863.

Desta Y, Gabbiye N and Alemu A. (2019). Advances of Science and Technology. 6th EAI International Conference, ICAST 2018. New York: Springer International Publishing.

Dullien FAL. (1991). Pore structure. In: Howard Brenner (ed.), Porous Media. Fluid Transport and Pore Structure. 2nd ed. San Diego, CA: Academic Press, pp.5-115.

Fradique M, Batista AP, Nunes MC, et al. (2010). Incorporation of Chlorella vulgaris and Spirulina maxima biomass in pasta products. Part 1: Preparation and evaluation. J Sci Food Agric 90: 1656-1664.

Gouveia L, Batista AP, Miranda A, et al. (2007). Chlorella vulgaris biomass used as colouring source in traditional butter cookies. Innov Food Sci Emerg Technol 8: 433-436.

Hutchings JB. (1999). Food color mechanisms. In: Chapman \& Hall (eds), Food Colour and Appearance. Gaithersburg, MD: Aspen Publishers, pp.453-592.

ISO Standard International. (2009). ISO 13320: Particle size analysis-laser diffraction methods.

Karkle EL, Keller L, Dogan H and Alavi S. (2012). Matrix transformation in fiber-added extruded products: Impact of different hydration regimens on texture, microstructure and digestibility. J Food Eng 108: 171-182.

Keawpeng I, Charunuch C, Roudaut G and Meenune M. (2014). The optimization of extrusion condition of phatthalung sungyod rice extrudate: A preliminary study. Int Food Res J 21: 2299-2304.

Larrea M, Chang Y and Martínez Bustos F. (2005). Effect of some operational extrusion parameters on the constituents of orange pulp. Food Chem 89: 301-308.

Mezreb K, Goullieux A, Ralainirina R and Queneudec M. (2003). Application of image analysis to measure screw speed influence on physical properties of corn and wheat extrudates. J Food Eng 57: 145-152.

Mohamed S. (1990). Factors affecting extrusion characteristics of expanded starch-based products. J Food Process Preserv 14: 437-452.

Morales P, Berrios JDJ, Varela A, et al. (2015). Novel fiberrich lentil flours as snack-type functional foods: An extrusion cooking effect on bioactive compounds. Food Funct 6 : 3135-3143.

Oikonomou NA and Krokida MK. (2011). Literature data compilation of WAI and WSI of extrudate food products. Int J Food Prop 14: 199-240.

Onyango C, Noetzold H, Bley T and Henle T. (2004). Proximate composition and digestibility of fermented 
and extruded uji from maize-finger millet blend. $L W T$ Food Sci Technol 37: 827-832.

Patil RT, De J Berrios J, Tang J, et al. (2005). Physical Characteristics of Food Extrudates - A Review. II: 2005 ASAE Annual International Meeting, p. 17.

Robertson JA, de Monredon FD, Dysseler P, et al. (2000). Hydration properties of dietary fibre and resistant starch: A European collaborative study. LWT Food Sci Technol 33: 72-79.

Saldanha do Carmo C, Varela P, Poudroux C, et al. (2019). The impact of extrusion parameters on physicochemical, nutritional and sensorial properties of expanded snacks from pea and oat fractions. LWT Food Sci Technol 112: 108252. https://doi.org/10.1016/j.lwt.2019.108252

Šárka E, Smrčková P, Chena Aldao DA, et al. (2015). Influence of process parameters and added starches on resistant starch content and sensory properties of maize extrudates. Starch/Staerke 67: 737-744.

Singh N and Smith AC. (1997). A comparison of wheat starch, whole wheat meal and oat flour in the extrusion cooking process. J Food Eng 34: 15-32.

Talens P, Martínez-Navarrete N, Fito $\mathrm{P}$ and Chiralt A. (2002). Changes in optical and mechanical properties during osmodehydrofreezing of kiwi fruit. Innov Food Sci Emerg Technol 3: 191-199.

Uribe-Wandurraga ZN, Igual $\mathrm{M}$, García-Segovia $\mathrm{P}$ and Martínez-Monzó J. (2019). Effect of microalgae addition on mineral content, colour and mechanical properties of breadsticks. Food Funct 10: 4685-4692. 